\title{
Psychological Distress In Canadian Men And Women With Posttraumatic Stress Disorder: Exploring The Differential Role Of Social Support
}

Ken Fowler ( $\boldsymbol{\nabla}$ kenfowler@mun.ca )

Memorial University of Newfoundland Libraries

Nyissa Walsh

Memorial University of Newfoundland

David Morgan

Memorial University of Newfoundland

Research article

Keywords: Posttraumatic Stress Disorder; Psychological Distress; Social support; Gender Differences;

Canadian Adults

Posted Date: March 13th, 2020

DOl: https://doi.org/10.21203/rs.3.rs-17103/v1

License: (9) This work is licensed under a Creative Commons Attribution 4.0 International License.

Read Full License 


\section{Abstract}

Background: Individuals with Posttraumatic Stress Disorder (PTSD) experience significant levels of psychological distress which is often moderated by social support. PTSD prevalence and symptomology gender differences tend to exist, and this may have important implications for the potential differential impact of social support.

Objectives: The primary objectives of this study were to explore levels of psychological distress and social support in a sample of 364 Canadian adults reporting a PTSD diagnosis by a health professional, and to examine the link between specific social support types and psychological distress overall, and for males and females separately.

Methods: Using a cross-sectional, national data file, 117 male and 247 female Canadian adults aged 2064 reporting PTSD were profiled using the Social Provisions Scale - Short Form (SPS-SF), and the Kessler Psychological Distress Scale (K10), and compared to a sex, age and frequency matched control group without a PTSD diagnosis. Social support subtype scores were subsequently regressed onto psychological distress.

Results: The PTSD sample had psychological distress scores that were more than double that of the matched control group, and were significantly lower in overall social support, and on each subscale. A diagnosis of PTSD was found to moderate the effect of social support on psychological distress, and while higher social integration and income predicted lower distress overall, higher reliable alliance scores, personal income, and lower age predicted lower distress for men, and higher social integration but lower guidance scores predicted lower distress for women.

Conclusions: Social support subtypes were differentially associated with psychological distress experienced by those with PTSD depending on gender, and this may have important implications for clinical practice.

\section{Background}

Posttraumatic Stress Disorder (PTSD) is a debilitating diagnosis that can result following exposure to traumatic events such as combat, violent assaults, natural disasters, car accidents, or the sudden loss of a loved one [1,2]. Sufferers of PTSD may become easily startled and angered, and resort to maladaptive behaviors such as drug use, or excessive alcohol consumption [1, 3]. Significant emotional changes can also lead to functional impairments [4, 5], heighten suicidal ideation risk [6], and interpersonal problems with family and friends [7]. PTSD is often comorbid with anxiety disorders or major depression, yielding deleterious, non-specific symptoms such as psychological distress which can serve to complicate proper assessment, and influence the presentation of other psychiatric conditions [8]. The estimated lifetime PTSD prevalence rate in the United States is roughly 7\% [8], while the Canadian rate has been assessed at $9.2 \%[1]$. 
Much research into the reduction and regulation of PTSD symptoms has considered the influence of social support [e.g., 6, 9, 10,11,12,13]. Social support may be generally defined as the recognition that one has access to the assistance and/or resources of others, as well as an over-all sense that one is cared for, particularly during crises $[14,15]$. Social support is commonly explored through the assessment of different domains which may be fundamentally classified as either tangible (e.g., financial assistance, transportation, provision of health-related information, and aid with daily activities) or intangible (e.g., emotional support, a sense of feeling valued, or being affiliated with others) $[9,16,17]$, and may extend from interpersonal, proximal relationships, to the influence of more distal, community-level characteristics such as social capital [16].

Studies exploring PTSD symptomology and psychological distress have widely observed social support to be one of the most consistent and principal covariates [18]. Further, observed associations between PTSD symptoms and social support have often been interpreted as evidence for its protective or salutary effect [19]. This perspective (often referred to as the social causation hypothesis) suggests that wellbeing is promoted by the availability of social support resources, and that deficiencies may lead to higher psychological distress [20]. Consistent with this notion, many studies have indeed proposed social support's health enhancing influence within the context of PTSD whereby positive social relations (particularly with family and close friends) generally predict better managed PTSD symptoms following a traumatic event $[9,10,11,21,22,23]$.

However, longitudinal studies exploring the association between social support and PTSD symptoms have also observed evidence to suggest that that the causal direction may actually work the other way [e.g., 19, 20]. According to the social erosion hypothesis, longer-term PTSD symptomology such as irritability/anger, and feelings of detachment may serve to negatively impact relationship quality, thus compromising social support resources $[5,19,20]$. As corroborating evidence, Kotler, lancu, Efroni, and Amir (2001) found that, compared with non-PTSD anxiety disorder respondents, and non-PTSD controls, respondents with PTSD reported significantly lower social support [24].

In addition to duration of PTSD symptomology, research also suggests that symptom type may have implications in terms of the PTSD-social support causal association. Specifically, PTSD may either involve distinct symptomology clusters such as hyperasoursal, avoidance, and intrusion symptoms [25], and/or non-specific symptoms such as psychological distress [8]. It has been proposed that specific PTSD symptoms could either be attenuated by social support (and therefore be explained via the social causation model), and/or serve to erode social support, whereas, psychological distress may primarily serve to erode social support [20]. Using social support and PTSD symptom data collected from a sample of National Guard soldiers at different time periods following combat deployment in Iraq, Shallcross et al. (2016) found evidence to suggest this very hypothesis - i.e., a bidirectional relationship between social support and PTSD-specific symptoms, and a unidirectional relationship between social support and psychological distress whereby prolonged distress exerted tension and pressure on social resources [20]. Taken together, while the unidirectional nature is an interesting notion certainly worthy of further investigation, it seems evident that psychological distress is itself a logical and valuable non-specific 
PTSD variable to explore when assessing the wellbeing of those with such a diagnosis, particularly within the context of its association with social support [20].

\section{PTSD, Gender Differences and Social Support}

While research consistently indicates that women are twice as likely to develop PTSD [3, 26, 27], there is also evidence to suggest gender differences in symptomology. For instance, based on the DSM-5 PTSD diagnostic criteria, Murphy, Elklit, Chen, Ghazali, and Shevlin (2018) reported that women scored higher on emotional cue reactivity while men tended to report more self-destructive behaviours [28]. Similarly, Meyer, Konecky, Kimbrel, DeBeer, Marx, Schumm et al. (2018) observed that functional impairment for men may be more reflective of distorted negative perceptions and distancing from others, while women's functional impairment may be primarily influenced by rage, over-alertness, carelessness, and insomnia [29].

The fact that PTSD prevalence and symptom disparities exist between men and women may also have significant implications for the potential impact of social support. For instance, in a study by Andrews, Brewin and Rose (2003), male and female victims of violent crime were assessed for PTSD symptoms as a function of social support at one and six month intervals [30]. While access to social support was associated with fewer occurrences of PTSD, as well as reduced symptom severity, it was also found that females were significantly more likely to experience negative reactions from their social networks, ranging from a perceived lack of concern about wellbeing, to overt negative responses such as placing responsibility on the victims themselves. Interestingly, Andrews et al. (2003) also found that females were increasingly more sensitive to negative reactions compared to males, and that negative reactions were a much stronger predictor of later PTSD onset [30].

\section{The present study}

While PTSD prevalence, symptomology, and comorbidities have been previously reported for the Canadian population [e.g., 1], we are unaware of research that has specifically explored the psychological distress and social support of those with PTSD, particularly within the context of gender. Further, to our knowledge, studies have not examined psychological distress of those with PTSD as a function of specific social support types. Indeed, contemporary research into the social support-PTSD association has suggested that comparisons between different social support types would be a valuable avenue for future research [e.g., 20].

Consequently, using data extracted from a large Canadian population health survey, the primary objectives of this study were to 1) establish levels of psychological distress, and social support (overall and by type) in a sample of adult male and female Canadian adults reporting a current diagnosis of PTSD, and compare them with levels from a matched, non-PTSD sample. Additionally, we wanted to determine if a PTSD diagnosis moderated the relationship between social support and psychological distress, and whether particular social support subtypes predicted psychological distress for the overall PTSD sample, and for males and females separately. It was hypothesized that 1) men and women with 
PTSD would report significantly higher levels of psychological distress, and lower levels of social support (overall and for each subtype) compared to the matched, non-PTSD control sample, 2) a PTSD diagnosis would significantly moderate the relationship between social support and psychological distress, and 3 ) the association between particular social support types and psychological distress would differ between men and women given documented differences in PTSD prevalence and symptomology.

As a special note, this research is admittedly exploratory in nature as we do recognize limitations in utilizing self-reported diagnosis PTSD data extracted from a national survey. More specifically, there is unfortunately no information on the kind of health professional providing the diagnosis, nor the type of trauma, and degree of exposure influencing the development of PTSD. However, since much of research into the potential influence of social support on PTSD symptoms tends to involve specific samples, such as those recruited from clinical treatment programs [e.g., 31], the current investigation stands to broaden the generalizability of the findings by utilizing a large sample, nationally representative adult health survey conducted in Canada.

\section{Method}

\section{Participants and Procedure}

Data for this study were extracted from the Public Use Microdata file of the Canadian Community Health Survey - Mental Health (CCHS-MH, 2012) [32], a cross-sectional, national survey with a response rate of 79.9. The file contains data associated with 25,113 respondents 15 years of age and older, representing each Canadian province. Information regarding the CCHS-MH questionnaire, sampling, and data collection procedures may be accessed at http://www23.statcan.gc.ca/imdbbmdi/instrument/3226_Q1_V9-eng.htm.

\section{Measures}

PTSD Diagnosis. For the current study, participants between the age of 20 and 64 were included if they answered "yes" to an item which asked whether they have been diagnosed with PTSD by a health professional that lasted, or was expected to last more than 6 months. As a clarity note, this variable assumes that the PTSD diagnosis is current, and does not reflect a lifetime prevalence whereby the condition may have occurred at one point in the respondent's past.

The resulting PTSD sample contained 364 respondents representing each Canadian province, with 117 males and 247 females. An age, sex, and frequency matched control group of 364 adults not reporting a PTSD diagnosis (i.e., 117 males and 247 females) was randomly sampled from the remaining CCHS-MH (2012) file.

Social Provisions Scale - Short Form (SPS-SF). Social Support was examined using the SPS-SF, a 10 item instrument adapted from the original long form scale measuring different aspects of social support including attachment, social integration, reassurance of worth, reliable alliance, and guidance [33]. During 
administration, respondents are asked to '... indicate how much each statement describes your situation by using these responses" which ranged from "there are people I can depend on to help me if I really need it", to "there are people who enjoy the same social activities I do", to "there are people I can count on in an emergency", etc. Participant responses were based on a four-point scale ranging from strongly disagree to strongly agree, with higher scores indicating more perceived social support. The Cronbach alpha for the global scale is 0.880 and the alphas for the five subscales have been observed to range between 0.528 and 0.690 [34].

The Kessler Psychological Distress Scale (K10). The K10 was used to obtain an assessment of participant psychological distress [35]. The 10 items of this scale are specifically designed to capture participants' mood and anxiety during the past month, e.g., "During the past month, about how often did you feel so depressed that nothing could cheer you up?" Participants then rate each question on a scale from $0=$ none at all to $4=$ all of the time. The scores for each item are then summed to produce potential overall score ranging between 0 and 40. Low scores are indicative of lower levels of psychological distress whereas higher scores are reflective of higher levels of psychological distress.

Age, Gender, and Income. In addition to self-reported age and gender, socioeconomic status was captured using reported personal annual income classified as less than $\$ 10,000, \$ 10,000-\$ 19,000$, $\$ 20,000-\$ 29,000, \$ 30,000-\$ 39,000, \$ 40,000-\$ 49,000$, or greater than $\$ 50,000$ [32].

\section{Data Analysis}

Independent sample t-tests were conducted to compare the PTSD sample's psychological distress, overall SPS-SF, and five SPS-SF subscales to that of the age, sex, and frequency matched, non-PTSD control. Independent sample t tests were subsequently carried out to compare male and female PTSD respondents in terms of psychological distress, overall SPS-SF, and each SPS-SF subscale. A moderator analysis was conducted to test whether the relationship between psychological distress and overall SPSSF was dependent on a diagnosis of PTSD. Finally, hierarchical regressions with a two-block structure were conducted to determine whether subscales of the SPS-SF predicted psychological distress for the PTSD group overall, and for males and females separately, after statistically controlling for age, sex, and income in Block 1.

\section{Results}

Comparisons between the PTSD and matched control samples in terms of psychological distress and social support means are presented in Table 1. As the table shows, the psychological distress mean for the PTSD sample $(M=14.1, S D=8.30)$ was significantly higher than the matched control sample $(M=$ $5.83, \mathrm{SD}=5.71)[t(723)=15.72, \mathrm{p}<.001, \mathrm{~d}=1.16]$. In terms of social support, Table 1 shows that the PTSD sample was significantly lower compared to the matched control sample overall $(M=32.94, S D=$ 5.76) $[t(705)=-7.63, p<.001, d=0.58]$, and for each SPS-SF subtype; i.e., attachment $(M=6.72, S D=1.3)$ $[t(723)=-5.86, p<.001, d=0.43]$, guidance $(M=6.77, S D=1.29)[t(724)=-6.23, p<.001, d=0.46]$, reliable alliance $(M=6.79, S D=1.32)[t(725)=-6.53, p<.001, d=0.48]$, social integration $(M=6.99, S D=1.11)$ 
$[\mathrm{t}(719)=-8.25, \mathrm{p}<.001, \mathrm{~d}=0.60]$, and reassurance of worth $(\mathrm{M}=6.46, \mathrm{SD}=1.33)[\mathrm{t}(713)=-5.75, \mathrm{p}<.001$, $\mathrm{d}=0.43]$.

Table 2 provides psychological distress and social support means for the PTSD sample by gender. The table shows that the male psychological distress mean of $13.13(S D=8.13)$ and the female mean of $14.62(S D=8.34)$ were not significantly different. Further, while PTSD females $(M=6.81, S D=1.28)$ reported significantly higher levels of attachment $(M=6.52, S D=1.32)[t(360)=-2.008, p<.05, d=0.22]$, no significant differences were found in terms of guidance, reliable alliance, social integration or reassurance of worth (See Table 2).

\section{Predictors of Psychological Distress}

A moderator analysis was carried out by performing a multiple regression with an interaction term to test whether a PTSD diagnosis moderated of the relationship between overall social support and psychological distress. Accordingly, the result was significant $\left(R^{2}=0.138, F(2,16518)=12.63, p<0.001\right)$, with a small effect size $(d=.016)$ [36]. These results can be seen in Fig. 1 , and indicate that while a significant, inverse relationship between social support and psychological distress was observed for those with and without a diagnosis of PTSD, the slope differentials revealed that the relationship was significantly stronger for those reporting a PTSD diagnosis.

Table 3 presents hierarchical regression analysis output for the overall PSTD sample which examined whether social support types predicted psychological distress after controlling for age, total personal income, and gender in Block 1. Accordingly, total personal income $(B=-.932, S E=.285, p<0.05)$ and gender $(B=2.903, S E=.965, p<0.05)$ were significantly associated with distress, accounting for $6.7 \%$ of the variance $(F(3,335=8.060, p<0.001)$. Specifically, lower personal income and being female were associated with higher levels of distress. In Block 2, psychological distress was significantly related to two particular social support subscales, i.e., guidance $(B=.675, S E=.560, p<0.05)$, and social integration $(B=-2.47, S E=.396, p<0.05)$, accounting for an additional $21.9 \%$ of the variance. Specifically, higher guidance scores were associated with higher distress, while higher social integration scores were associated with lower distress.

Hierarchical regression results for male PTSD respondents are presented in Table 4. In Block 1, age (B $=.734, \mathrm{SE}=.322, \mathrm{p}<0.05)$ was positively associated with distress, while total personal income $(\mathrm{B}=$ $-1.803, S E=.489, p<0.001)$ was inversely related, accounting for $14.3 \%$ of the variance. In Block 2 , reliable alliance was the lone significant predictor of distress $(B=-2.581, S E=.854, p<0.05)$. This was an inverse relationship, and accounted for an additional $29.3 \%$ of variance (See Table 4 ).

For the female PTSD sample, there were no significant predictors in Block 1 in terms of age or total personal income $(0.9 \%$ of variance accounted for). However, both guidance $(B=1.374, S E=.690, p<$ $0.05)$, and social integration $(B=-2.816, S E=.444, p=0.001)$ did significantly predict psychological distress in Block 2, accounting for $26.6 \%$ of additional variance (See Table 5). Specifically, guidance was positively associated with distress, while social integration was inversely related. 


\section{Discussion}

Consistent with previous studies [e.g., 4, 37], psychological distress for the PTSD sample was significantly higher than the non-PTSD matched sample. Also in line with research reporting negative social consequences as a function of PTSD [7, 24], significantly lower levels of social support were observed overall, and for each of the five sub-categories including attachment, social integration, reassurance of worth, reliable alliance, and guidance. The fact that the entire spectrum of social support subtypes assessed by the SPS-SF was lower for the PTSD sample is an important consideration given the proposition that diverse social support resources are necessary to reduce the risk of social and emotional isolation which could translate into a variety of negative outcomes including distress, poor cognitive ability, deprived sleep, and social detachment, resulting in depression and poor life satisfaction [38].

In terms of the regression analysis conducted using PTSD diagnosis as a moderator of the relationship between overall social support and psychological distress, higher social support was associated with lower psychological distress for respondents with and without a diagnosis of PTSD; however, the effect was significantly stronger for the PTSD sample. Hence, depending on which causal hypothesis one may assume (i.e., social causation or social erosion) [20], it would appear that social support's salutary properties may be even more important for the mental health of PTSD sufferers, or psychological distress may have a more detrimental impact social support within the context of PTSD.

While gender emerged as a significant predictor in the overall hierarchical regression, implicating higher psychological distress among the female PTSD group, no significant difference was observed when psychological distress scores were compared between PTSD males and females, a finding contrary to those noted in the general population whereby women typically have significantly higher levels [e.g., 39]. Despite the fact that gender comparisons for social support in the PTSD sample yielded little in terms of significant differences, PTSD women did report significantly higher levels attachment, a finding consistent with the Meyer et al. (2018) study suggesting that functional impairment for men may reflect distancing from others [29]. In terms of the potential social support-PTSD causal relationship, this may raise an interesting question as to whether social erosion may be more likely among male PTSD sufferers, and hence an important topic for future studies.

When age, gender, personal income, and subtypes of social support were regressed onto psychological distress for the entire PTSD sample, two variables emerged in Block 1, including gender (as previously mentioned), and total personal income, while social integration and guidance emerged in Block 2. In terms of social integration, higher scores were associated with lower psychological distress, a finding that has been previously reported within the context of PTSD risk and symptomology [e.g., 11, 21, 40]. It would seem that such studies insinuate a social causation perspective suggesting that the salutary influence of social support serves to attenuate the impact of PSTD. For instance, it has been proposed a higher sense of connectedness (particularly with close family and friends) may be beneficial in providing positive 
alterations to posttraumatic cognitions, which in turn may result in improvement from overall PTSD symptoms [41].

The potential health enhancing influence of social integration within the context of PTSD may also be partially explained by a sense of identification with, or similarly to others in one's social network. Indeed, inherent in the SPS-SF items associated with the social integration subscale is a sense of sharing similar attitudes and beliefs with others. In the case of combat scenarios, for instance, this certainly makes intuitive sense as military personnel share a very close and unique bond in terms of training, family life, risks, combat experiences, etc. This reasoning also appears consistent with research reporting that veterans with combat exposure were less likely to develop PTSD when they reported having strong relations with fellow veterans, and that such connections were stronger predictors of later PTSD than family or other community relations [e.g., 13].

Since female respondents outnumbered male respondents 2:1 in the current study's PTSD sample, it is not surprising that social integration also emerged as a primary predictor when a separate hierarchical regression analysis was conducted for the female PTSD group. Given that sexual assault is a common PTSD-inducing trauma among women $[1,3,26]$, perhaps the support-provider's perceived similarity to (or identification with) a victim's experience is another key factor associated with lower psychological distress levels in this particular context.

The regression analysis featuring the male PTSD sample revealed three significant variables, i.e., total personal income and age in Block 1 , and reliable alliance (i.e., having a network one can rely on during emergencies) in Block 2. Given that total personal income was evident in the overall sample, such an observation may be more reflective of the type of traumatic event experienced within the entire PTSD sample. For instance, in the case of natural disasters, it seems feasible that financial means could indicate a person's greater capacity to manage various resulting challenges, thus leading to relatively lower distress levels. Indeed, studies into natural disasters do show that support in the form of material resources such as food and shelter certainly serve to address a significant source of distress [e.g., 42].

However, in the case of medical emergencies (where the likelihood tends to increase with age - another significant predictor for men in Block 1), people are more likely to experience restrictions in their physical abilities and hence challenges in the form of daily activity limitations, which may certainly result in significant distress $[43,44]$. In this scenario, while access to reliable alliance support could be quite beneficial in regards to buffering overall distress, the fact that it surfaced primarily among the male PTSD group seems comparable to research which has found that tangible support, including assistance from others, was not a significant predictor of later development of PTSD in a sample of sexual assault victims [44]. It also seems similar to findings in depression research whereby tangible support (i.e., daily activity support) was more likely to predict shorter depression duration in men and not women $[16,17]$.

Perhaps one of the most interesting findings of the current study was that the SPS-SF subscale of 'guidance' emerged as a positive predictor of psychological distress among PTSD women. Given that the two items associated with this subscale included "I have someone to talk to about decisions in my life" 
and "I have a trustworthy person to turn to if I have problems", it would seem that a theme of 'advice giving' is representative. Moreover, in the sexual assault literature, a frequently cited risk relates to the potential for social contacts to be overbearing and opinionated following a victim's disclosure $[45,44,46]$. Although intentions are meant to be supportive, such assertive responses on behalf of confidants may subsequently result in a victim's sense of lack of control, and consequently a greater likelihood of avoidance behavior $(47,45,46]$, two scenarios with a capacity to facilitate the onset of PTSD $[44,45,47]$. However, if one were to truly question the causal direction within the context of both the social causation and social erosion models, two scenarios seem likely; 1 ) interestingly, it may be the case that social support operates on psychological distress in a deleterious way, resulting in more distress, or 2) psychological distress operates on social support, serving to increase one's perception of guidance availability. In any event, such propositions certainly represent lucrative issues of future inquiry.

\section{Limitations}

We acknowledge limitations of the current study. Perhaps most importantly, due to the design of the CCHS-MH data file, the specific type of trauma that might have resulted in the development of PTSD for participants was not reported. Indeed, future studies should include trauma type as a separate variable to gain further insight into the potential benefits and challenges of social support components, overall, and men and women separately. Other limitations of the study include the fact that data were cross-sectional and correlational (which precludes any inferences of causation). A final limitation would be that the data used for the current study were founded on self-reported diagnoses which can be problematic in terms of participant honesty, memory, comprehension, etc. However, the fact that we observed a 2:1 female to male ratio of reported PTSD in the CCHS-MH sample does alleviate some concerns about self-report reliability as it does reflect gender-prevalence differentials reported in the literature [e.g., 3, 14].

Additionally, as mentioned previously, using a sample of self-reported PTSD individuals allows us to capture a more generalizable sample of those suffering with PTSD. One could argue clinical research samples fail to include those individuals who are unable to or unwilling to obtain treatment and therefore provides a strength of external validity.

\section{Conclusion}

Adults with PTSD are at risk for comorbid psychiatric disorders, harmful psychological distress, and as well as lower levels of various forms of social support. There are also significant gender differences in regards to the types of social support factors that might predict overall psychological distress, and the onset of PTSD. Health-care professionals should be aware of such findings when dealing with cases related to PTSD.

\section{Declarations}

Ethics approval and consent to participate 
Since data used in this study were taken from a publically available Public Use Micro File (PUMF) from Statistics Canada, ethics approval and consent for participation were not required.

Consent for publication

Not Applicable.

Availability of data and material

The datasets generated and/or analysed during the current study are available in the Microdata Analysis and Subsetting with SDA, Faculty of Arts \& Science, University of Toronto repository, http://sda.chass.utoronto.ca/sdaweb/sda.ht .

Competing interests

There are no financial and non-financial competing interests.

\section{Funding}

No funding was obtained for this study.

Authors' contributions

All authors, KF, NW, and DM have read and approved the manuscript.

Acknowledgements

Not Applicable.

List of Abbreviations

PTSD - Posttraumatic Stress Disorder

SPS-SF - Social Provisions Scale-Short Form

K10 - Kessler Psychological Distress Scale

CCHS-MH, 2012 - Canadian Community Health Survey - Mental Health (2012)

\section{References}

1. Van Ameringen, M., Mancini, C., Patterson, B., \& Boyle, M. H. (2008). Post-traumatic stress disorder in Canada. CNS Neurosci Ther, 14(3), 171-181. doi: 10.1111/j.1755.5949.2008.00049x

2. American Psychiatric Association. (2013). Diagnostic and statistical manual of mental disorders $\left(5^{\text {th }}\right)$. Arlington, VA: American Psychiatric Publishing. 
3. Barlow, D. H., Durand, V. M., Stewart, S. H., \& Lalumiere, M. L. (2015). Abnormal Psychology: An integrative approach. Toronto, ON: Nelson Education Ltd.

4. McFarlane, A. C. (2000). Posttraumatic stress disorder: A model of the longitudinal course and the role of the risk factors. The Journal of Clinical Psychiatry, 61(5), 15-23.

5. Kaniasty, K., \& Norris, F. (2008). Longitudinal linkages between perceived social support and posttraumatic stress symptoms: Sequential roles of social causation and social selection. Journal of Traumatic Stress,21, 274-281.

6. Jing, G., Chengcheng, L., Dexia, K., Solomon, P., \& Mingqi, F. (2018). The relationship between PTSD and suicidality among Wenchuan earthquake survivors: The role of PTG and social support. Journal of Affective Disorders, 235(1), 90-95. doi.org/10.1016/j.jad.2018.04.030

7. Manguno-Mire, G., Sautter, F., Lyons, J., Myers, L., Perry, D., Sherman, M., Glynn, S., \& Sullivan, G. (2007). Psychological Distress and Burden among Female Partners of Combat Veterans with PTSD. The Journal of Nervous and Mental Disease, 195(2), 144-151. doi:

10.1097/01.nmd.0000254755.53549.69

8. Kessler, R. C., Chiu, W. T., Demler, O., \& Walters, E. E. (2005). Prevalence, severity, and comorbidity of 12-month DSM-IV disorders in the National Comorbidity Survey Replication. Archives of General Psychiatry, 62, 617-627. doi:10.1001/archpsyc.62.6.617

9. Flores, E. C., Carnero, A. M., \& Bayer, A. M. (2014). Social capital and chronic post-traumatic stress disorder among survivors of the 2007 earthquake in Pisco, Peru. Social Science and Medicine, 101, 917. doi: 10.1016/j.socscimed.2013.11.012

10. Tsai, J., Harpaz-Rotem, I., Pietrzak, R. H., \& Southwick, S. M. (2012). The role of coping, resilience, and social support in mediating the relationship between PTSD and social functioning in veterans returning from Iraq and Afghanistan. Psychiatry, 75(2), 135-149. doi: 10.1521/psyc.2012.75.2.135

11. Woodward, M. J., Eddinger, J., Henschel, A. V., Dodson, T. S., Tran, H. N., \& Beck, J. G. (2015). Social support, posttraumatic cognitions, and PTSD: The influence of family, friends and a close other in an interpersonal and non-interpersonal trauma group. Journal of Anxiety Disorders, 35, 60-67. doi: 10.1016/j.janxdis.2015.09.002

12. Lehavot, K., Der-martirosian, C., Simpson, T. L., Shipherd, J. C., \& Washington, D. L. (2013). The role of military social support in understanding relationship between PTSD, physical Health, and healthcare utilization in women veterans. Journal of Traumatic Stress, 26(6), 772-775. doi: 10.1002/jts.21859

13. Laffaye, C., Cavella, S., Drescher, K., \& Rosen, C. (2008). Relationships among PTSD symptoms, social support, and support source in veterans with chronic PTSD. Journal of Traumatic Stress, 21(4), 394-401. doi: 10.1002/jts.20348

14. Roberts, M. H., Klatzkin, R. R., \& Mechlin, B. (2015). Social support attenuates physiological stress responses and experimental pain sensitivity to old pressor pain. Annals of Behavioural Medicine, doi: $10.1007 / \mathrm{s} 12160-015-9686-3$

15. Seeman, T. E., Gruenewald, T. L., Cohen, S., Williams, D. R., \& Matthews, K. A. (2014). Social relationships and their biological correlates: Coronary artery risk development in young adults 
(CARDIA) study. Psychoneuroendocrinology, 43, 126-138. doi: 10.1016/j.psyneuen.2014.02.008

16. Fowler, K., Wareham-Fowler, S., \& Barnes, C. (2013). Social context and depression severity and duration in Canadian men and women: Exploring the influences of social support and sense of community belongingness. Journal of Applied Social Psychology, 43(1), E85-E96. doi:

$10.1111 /$ jasp. 12050

17. Wareham, S., Fowler, K., \& Pike, A. (2007). Determinants of depression severity and duration in Canadian adults: The moderating effects of gender and social support. Journal of Applied Social Psychology, 27, 2951-2979.

18. Ozer, E. J., Best, S. R., Lipsey, T. L., \& Weiss, D. S. (2003). Predictors of posttraumatic stress disorder and symptoms in adults: A meta-analysis. Psychological Bulletin, 129, 52-73. doi:10.1037//00332909.129.1.52

19. King, D.W., Taft, C., King, L.A., Hammond, C., \& Stone, E.R. (2006). Directionality of the Association Between Social Support and Posttraumatic Stress Disorder: A Longitudinal Investigation. Journal of Applied Social Psychology, 36(12), 2980-2992

20. Shallcross, S.L., Arbisi, P.A., Polusny, M.A., \& Kramer, M.D. (2016). Social Causation Versus Social Erosion: Comparisons of Causal Models for Relations Between Support and PTSD Symptoms. Journal of Traumatic Stress, 29, 167-175. doi: 10.1002/jts.22086

21. Carter, S., Loew, B., Allen, E., Stanley, S., Rhoades, G., \& Markman, H. (2011). Relationships between soldiers' PTSD symptoms and spousal communication during deployment. Journal of Traumatic Stress, 24(3), 352-355. doi: 10.1002/jts.20649

22. Guay, S., Billette, V., \& Marchand, A. (2006). Exploring the links between post-traumatic stress disorder and social support: Processes and potential research avenues. Journal of Traumatic Stress, 19, 327338. doi: 1002/jts.20124

23. Kouros, C. D., \& Garber, J. (2014) Trajectories of individual depressive symptoms in adolescents: gender and family relationships as predictors. Developmental Psychology. doi: 10.1037/a0038190

24. Kotler, M., lancu, J., Efroni, R., \& Amir, M. (2001). Anger, Impulsivity, Social Support, and Suicide Risk in Patients with Posttraumatic Stress Disorder. The Journal of Nervous and Mental Disease, 189(3), 162-167. doi:10.1097/00005053-200103000-00004

25. Simms, L. J., Watson, D., \& Doebbelling, B. N. (2002). Confirmatory factor analyses of posttraumatic stress symptoms in deployed and nondeployed veterans of the Gulf war. Journal of Abnormal Psychology, 111, 637-647. doi:10.1037/0021-843X.111.4.637

26. De Long, H. (2012). Social support in PTSD: an analysis of gender, race, and trauma type. Discussions, 8(2), Retrieved from http://www.inquiriesjournal.com/a?id=802

27. Olff, M., Langeland, W., Draijer, \& Gersons, B.P. (2007). Gender differences in posttraumatic stress disorder. Psychological Bulletin, 133(2), 183-204.

28. Murphy, S., Elklit, A., Chen, Y. Y., Ghazali, S. R., \& Shevlin, M. (2018). Sex Differences in PTSD Symptoms: A Differential Item Functioning Approach. Psychological Trauma: Theory, Research, Practice, and Policy. Advance online publication. http://dx.doi.org/10.1037/tra0000355 
29. Meyer, E.C., Konecky, B., Kimbrel, N.A., DeBeer, B.B., Marx, B.P., Schumm, J., Penk, W.E., Gulliver, S.B., Morissette, S.B. (2018). Gender differences in associations between DSM- 5 posttraumatic stress disorder symptom clusters and functional impairment in war veterans. Psychological Services, 15(2), 230-237.

30. Andrews, B., Brewin, C., \& Rose, S. (2003). Gender, social support, and PTSD in victims of violent crime. Journal of Traumatic Stress, 16(4), 421-427. doi: 10.1023/A:1024478305142

31. Guay, S., Beaulieu-Prevost, D., Beaudoin, C., St. Jean-Trudel, E., Nachar, N., Marchand, A., O’Conner, K.P., (2011). How do social interactions with a significant other affect PTSD symptoms? An empirical investigation with a clinical sample. Journal of Aggression, Maltreatment \& Trauma, 20(3), 280-303. doi:1080/10926771.2011.562478

32. Statistics Canada. (2013). Canadian Community Health Survey (CCHS)-Mental Health. Ottawa: Statistics Canada.

33. Cutrona, C. E. \& Russell, D. W. (1987). The provisions of social relationships and adaptation to stress. Advances in Personal Relationships, 1, 37-67.

34. Caron, J. (2013). A validation of the Social Provisions Scale: the SPS-10 items. Sante mentale au Quebec, 38(1), 297-318.

35. Kessler, R. C., Andrews, G., Colpe, L., Hiripi, E., Mroxczek, D., Normand S.,.. Zaslavsky, A. (2002). Short screening scales to monitor population prevalence and trends in non specific psychological distress. Psychological Medicine, 32, 959-976. doi:10.1017/S0033291702006074

36. Cohen, J. (1988). Statistical power analysis for the behavioural sciences (2nd ed.). Hillsdale, NJ: Lawrence Erlbaum.

37. Koren, D., Doron, N., Cohen, A., Berman, J., Klein, E.M. (2005). Increased PTSD risk with combatrelated injury: A matched comparison study of injured and uninjured soldiers experiencing the same combat events. The American Journal of Psychiatry, 162(2), 276-282.

38. Weiss, R. S. (1974). The provisions of social relationships. In Z. Rubin (Ed.), Doing unto others (pp. 17-26). Englewood Cliffs, NJ: Prentice Hall.

39. Mohr, Armeli, Mccauley Ohannessian, Tennen, Carney, Affleck, \& Del Boca (2003). Daily interpersonal experiences and distress: Are women more vulnerable? Journal of Social and Clinical Psychology, 22, 393-423. doi.org/10.1521/jscp.22.4.393.22895

40. Vernberg, F. M., LaGreca, A. M., Silverman, W. K., \& Prinstein, M. J. (1996). Prediction of posttraumatic stress symptoms in children after Hurricane Andrew. Journal of Abnormal Psychology, 105(2), 237248.

41. Kleim, B., Ehlers, A., \& Glucksman, E. (2007). Early predictors of chronic post-traumatic stress disorder in assault survivors. Psychological Medicine, 37(10), 1457-1467. doi: 10.1017/S0033291707001006

42. Heid, A. R., Pruchno, R., Cartwright, F. P., \& Wilson-Genderson, M. (2016). Exposure to Hurricane Sandy, neighborhood collective efficacy, and post-traumatic stress symptoms in older adults. Aging \& Mental Health 01, 1-9. doi: 10.1080/13607863.2016.1154016 
43. Dinenberg, R. E., Mccaslin, S. E., Bates, M. N., \& Cohen, B. E. (2014). Social support may protect against development of posttraumatic stress disorder: findings from the heart and soul study. American Journal of Health Promotion, 28(5), 294-297, doi: 10.4278/ajhp.121023-QUAN-511

44. Peter-Hagene, L. C, \& Ullman, S. E. (2014). Social reactions to sexual assault disclosure and problem drinking. Journal of Interpersonal Violence, 29(8), 1418-1437, doi: 10.1177/0886260513507137

45. Herbert, T. L., \& Dunkel-Schetter, C. (1992). Negative social reactions to victims: An overview of responses and their determinants. Hillsdale, NJ: Lawrence Erlbaum.

46. Sit, V., \& Schuller, R. A. (2015). Understanding support providers "views of "helpful" responses to sexual assault disclosures: The impacts of self-blame and physical resistance. Journal of Interpersonal Violence, doi: 10.1177/0886260515614563

47. Ullman, S. E., Townsend, S. M., Filipas, H.H., \& Starzynski, L. L. (2007). Structural models of the relations of assault severity, social support, avoidance coping, self-blame and PTSD among sexual assault survivors. Psychology of Women Quarterly 31(8), 23-387, doi: 10.1111/j.14716402.2007.00328.x

\section{Tables}

Due to technical limitations, all tables are only available for download from the Supplementary Files section.

\section{Figures}




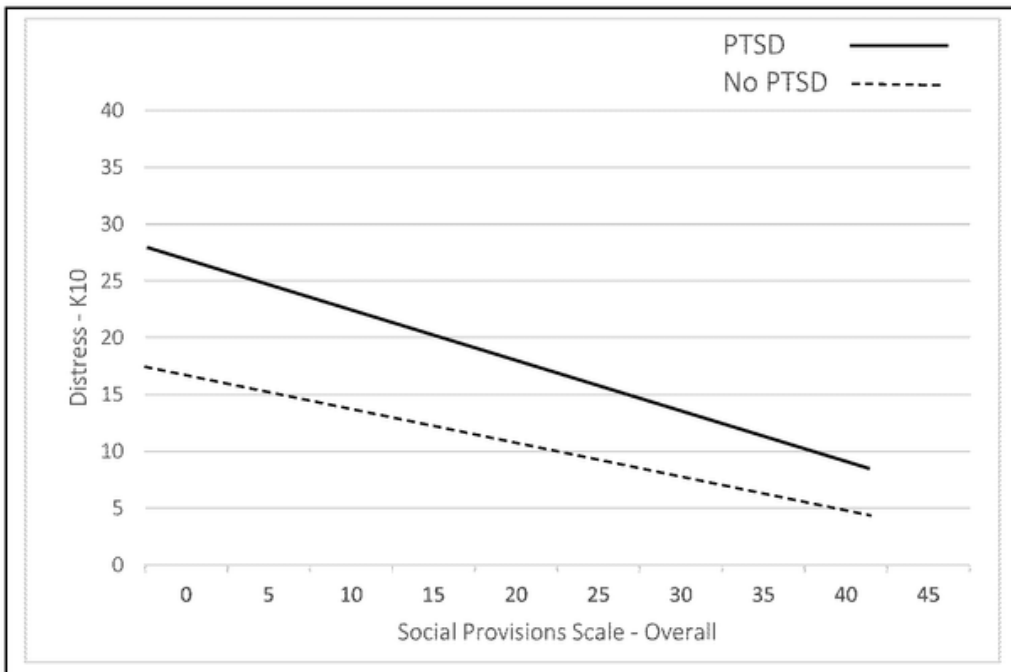

Figure 1 - Moderation effect of social support on psychological distress among PTSD and non-PTSD individuals

Figure 1

Moderation effect of social support on psychological distress among PTSD and non-PTSD individuals

\section{Supplementary Files}

This is a list of supplementary files associated with this preprint. Click to download. 
- PTSDandSocialSupportBMCTables.pdf 